\title{
Elutriation of fines from binary particle mixtures in bubbling fluidized bed cold model
}

\author{
Esmail R. Monazam², Ronald W. Breault ${ }^{* 1}$, Justin Weber ${ }^{1}$, Ky Layfield ${ }^{2}$ \\ ${ }^{1}$ National Energy Technology Laboratory \\ U. S. Department of Energy \\ 3610 Collins Ferry Rd. \\ Morgantown, West Virginia 26507-0880 \\ ${ }^{2}$ REM Engineering Services, PLLC \\ 3537 Collins Ferry Rd. \\ Morgantown, West Virginia 26505
}

\begin{abstract}
The elutriation of fine particles from a binary mixture of particles with different densities and diameters has been investigated in bubbling fluidized bed (BFB). A series of experiments were conducted in a $10 \mathrm{~cm}$ diameter, $170 \mathrm{~cm}$ tall cylindrical bubbling fluidized bed under various operating conditions. Bed materials with different particle sizes, ranging from $93 \mu \mathrm{m}$ to 1000 $\mu \mathrm{m}$ powder, and particle densities ranging from 7.9 to $2.45 \mathrm{gm} / \mathrm{cm}^{3}$ were used in these experiments. Various combinations of these solids were mixed and fluidized at several superficial gas velocities. Solid elutriation was measured by collecting the carryover solids exiting the column with a filter. Experimental data on the effects of particle density, particle size, and gas velocity on the elutriation of particles from bubbling fluidized bed of binary mixture are examined. Influence of weight fraction of fines in the binary mixture on coarse particles was also investigated and discussed. The results indicated that the elutriation rate constant increases with increasing superficial gas velocities and weight fraction of fines in the bed. A generalized correlation for the elutriation rate constant is proposed using the ratio of $U_{g} / U_{t}$, weight fraction of fines, and a fines to coarse particle density ratio.
\end{abstract}

\section{Introduction}

The United States Department of Energy (US DOE) has set a goal to modify the existing pulverized coal-fired (PC) power plants to remove over $90 \%$ of the total carbon in the coal as $\mathrm{CO}_{2}$ for use or sequestration [1]. Chemical Looping Combustion (CLC) is a novel technology, which has the potential to significantly reduce the energy penalty associated with carbon capture. The CLC process produces a binary mixture of $\mathrm{CO}_{2}$ and $\mathrm{H}_{2} \mathrm{O}$ in the flue gas where the $\mathrm{CO}_{2}$ can be separated simply by condensing the $\mathrm{H}_{2} \mathrm{O}$, similar to an oxy-fuel process. The unique characteristic of the CLC process is the use of a solid "oxygen carrier" to transport oxygen from the air to a separate fuel reactor, thus eliminating the contact between air and fuel streams [2].

\footnotetext{
* Corresponding author: Tel. 304-285-4486; fax: 304-285-4403; email: ronald.breault@ netl.doe.gov
} 
Interest in chemical looping combustion (CLC) technologies has grown significantly over the last five to ten years (Lyngfelt et al. [3]; Fan [4]; Hossain and de Lasa [5]). In recent years, extensive research has been conducted on CLC of gaseous fuels. However, CLC of solid fuels is a quickly-growing area of research, particularly in the area of future clean coal power generation systems. However, direct coal CLC is a relatively novel approach that presents new research issues such as removal of ash byproducts from the CLC process.

The fuel reactor typically contains a mixture of coal, char, ash, and the oxygen carrier. The oxygen carriers typically considered are metal oxides such as $\mathrm{Fe}_{2} \mathrm{O}_{3}, \mathrm{CuO}$. The ash and char present in CLC is typically smaller and lighter than metal oxide bases oxygen carriers. Although the impact of ash on the oxygen carrier reaction kinetics is minimal (Siriwardane et al. [6]; Rubel et al. [7]), the design and operation of chemical looping combustion requires the control of ash accumulation. More importantly, char cannot enter the air reactor. If it does, the carbon will not be captured.

One approach is to drain both the carrier and the ash from the system continuously. However this requires continuous feed of fresh oxygen carrier into the system resulting in a significant operational cost. The approach investigated in this paper involves direct separation of the ash and carrier from a bubbling fluidized bed using the different aerodynamic characteristics of both particles. The benefits of an aerodynamic based solid-solid separation process include: reducing the requirement for fresh oxygen carrier make-up, reducing solid waste streams, and reducing operating costs for carrier make-up.

The optimal design of solid-solid separation and technical and economic success of chemical looping combustion requires good predictive capability of the estimation of fines hold-up in the bed and the elutriation rate of fines from the bed. Although extensive investigation on elutriation rate have been made by many researchers [8-15], nearly all of the published correlations proposed relate mainly to larger particle systems, and they do not adequately predict the elutriation of very fine particles. Furthermore, almost none of them are applicable to the multiparticle system of different densities with mixing patterns that related to particle concentration.

Recently, Chew et al. [16] reviewed a significant number of entrainment correlations in gas-solid fluidization from the literature. They have listed about 28 equations to predict the elutriation rate constant by different authors. It was concluded that the discrepancies in predicting elutriation rate constant are up to 20 orders of magnitude. Therefore, the review suggests the need for more physical understanding of the dominating factors affecting entrainment. The correlations reviewed by Chew et al. are for the elutriation of fines from a bed consisting of a single material, i.e. a single density. That is to say, they do not cover the elutriation of fines from a low density solid from a bed of high density coarse material as is the case in chemical looping combustion system applications. This being said, there is significantly paucity in the literature for binary (poly-density) data and the specific influence of density differences on elutriations rate.

In the literature reviewd by Chew et al., the elutriation rate constant are usually expressed by operating conditions and the driving force is proportional to the difference between gas velocity and terminal velocity $\left(\mathrm{U}_{\mathrm{g}}-\mathrm{U}_{\mathrm{t}}\right)$ of the particle. Other relevant research in this field such as Geldart et al. [17] found that the elutriation rate increases sharply with the gas velocity close to the terminal velocity. Note that elutriation occurs at velocities less than the terminal velocity in this work by Geldart et al. Therefore, it is clear that that the elutriation rate needs to be defined such that the resulting correlation covers that observation and the use of $U_{g}-U_{t}$ provides a negative value for these conditions $\left(\mathrm{U}_{\mathrm{g}}<\mathrm{U}_{\mathrm{t}}\right)$. 
Liu and Kimura [18] observed the fine particles controlled the elutriation of mixtures of fine and coarse particles. Geldart and Pope [19] reported that the existence of fine particles promotes the elutriation of coarse particles from a fluidized bed with mixture of fine and coarse particles. Li et al. [20] report the elutriation rate constant of group $C$ and group A particles to be dependent on the weight fraction of the group $\mathrm{C}$ particles in the bed. They stated that an increased in fraction of superfine decreases the elutriation rate of the fines due to increase of interparticle adhesion. Geldart et al. [21] reported that the addition of a small quantity of Geldart-C particles caused a decrease in elutriation due to fines adhering to the large particles.

Cocco et al. [22] suggesting that the particle cluster in fluidized bed has a great influenced on the elutriation rate of fine particles. In that work, Cocco et al. [22] discuss how elutriation is decreased due to the fines forming clusters and act like larger particles such that they fall back into the bed. They tested this by placing baffles near the top of the bed to break up the clusters and discovered that under high shear conditions (high superficial velocities) the elutriation was much higher when the baffles were present.

Baeyens et al. [xx] investigated the effect of adding a small fraction of fines of different densities to a distribution of Group A powders (noted as E-Cat and zircon). They report that for these conditions, the density of the fines had little effect upon the entrainment rate. Cocco et al. [22] report that the fines density might be a factor. In the present work, Group A fine material is added to a bed of Group B material. Under these conditions, the fines density, or rather the ratio of the fines density to the coarse density clearly effected the elutriation rate.

The objective for this work was to understand elutriation of glass bead fines (a surrogate for fine ash particles generated in coal CLC applications) from a bed of larger denser material (steel shot, ilmenite and alumina as surrogates for the oxygen carrier in CLC applications). The goal of this work is to develop a general correlation that could be used to predict the elutriation rate of low density fine particles in a bubbling fluidized bed of larger dense particles, as well as to investigate the effect of fine fraction on elutriation rate.

\section{Experimental}

The experimental apparatus used in this work is shown in Figure 1 . The fluidized bed is $10 \mathrm{~cm}$ in diameter and $170 \mathrm{~cm}$ tall and constructed with a clear acrylic pipe. The $10 \mathrm{~cm}$ column used in this study is larger than $44 \%$ of the reported investigations in the review paper by Chew et al. [16] Additionally, it is comparable with two of the investigations in that review such that the 10 $\mathrm{cm}$ column used in this study is larger or comparable in size with more than $50 \%$ of the work discussed in the review. Furthermore, Chew et al. [16] did not report finding a systematic trend in the elutriation predictions that would be indicative of a small diameter bias.

The fines exit the bed through a $5 \mathrm{~cm}$ ID port at $90^{\circ}$ at the top of the bed where a micro-sized fabric filter bag is attached and captures the fine particles being elutriated. Compressed air is used as the fluidizing gas which is controlled by a mass flow controller. A perforated plate with 25 symmetrical orifices, $1.59 \mathrm{~mm}$ in diameter, was used as the gas distributor. A U.S. No. 325 mesh sized $(44 \mu \mathrm{m})$ stainless steel screen was placed at the bottom of the gas distributor to prevent material in the fluidizing bed from escaping into the plenum chamber. Experiments were performed by closing the air vent valve connected to an opening in the plenum chamber, thus directing the flow through the gas distributor and into the fluidized bed. The experiment would run for the allocated sampling time and then the air vent valve would be opened, releasing the air flow directed to the bed into the atmosphere. The filter bag was weighed after each test run to determine the weight of the material collected, as compared to the empty bag before use. The 
elutriated fine and coarse particles were separated by a U.S. sized 200 mesh (74 $\mu \mathrm{m})$ sieve. Once separated, the fine and coarse particles were weighed separately to determine the mass percentages of the material that had been elutriated during the experiment. The amount of material captured in-between runs was recorded and then returned to the bed in order to maintain a constant bed inventory. The experiments were conducted under batch mode operating conditions.

In this study, ilmenite, $\mathrm{Al}_{2} \mathrm{O}_{3}$, and steel shot were used as coarse particles and glass beads were uses as fine particles. Tables 1 and 2 show the physical properties of particle mixtures and the operating conditions used in the experiments.

The initial particle size distributions are shown in Figure 2. Steel shot particles can be classified as Geldart-B particles, ilmenite particles as Geldart-B particles, $\mathrm{Al}_{2} \mathrm{O}_{3}$ (small) as Geldart-B particles, $\mathrm{Al}_{2} \mathrm{O}_{3}$ (large) as Geldart-D particles and glass beads a Geldart A/B particles.

In these experiments, the static bed depth, which consisted of the fine particles (glass beads) and coarse particles (ilmenite, either of the two alumina oxides, and steel shot), was maintained at $7.62 \mathrm{~cm}$ at start of testing. However, when varying the weight percentage of the fine particles, the relative depth for both particles varied accordingly. All experiments were run at ambient conditions. For all the experiments the freeboard height was always well above TDH and hence both the size distribution and entrainment rate become nearly constant. This large height of freeboard also avoid on overestimate of elutriation rate. The TDH was calculated using the following correlation [23]:

$$
T D H=3.87 \times 10^{-2} d_{p}^{-0.54} \rho_{s}^{-0.04} U_{g}^{0.41} D_{b}^{0.97}(1)
$$

The calculate TDH was in the range of $0.32-0.56 \mathrm{~m}$ which is significantly less than the available $1.6 \mathrm{~m}$.

The coarse particles were selected to generate data relevant for typical oxygen carriers in chemical looping combustion. Ilmenite is an oxygen carrier that has been used quite extensively. Aluminum oxide was chosen because fabricated nickel and copper based oxygen carriers are typically supported on alumina whereas the steel shot represents an extremely high density case. In a chemical looping process that uses coal as fuel, it is envisioned that pulverized coal will be used with the particle size on the order of 10 to $100 \mu \mathrm{m}$. Unfortunately, real ash particles could not be obtained for the presented studies so glass beads were used as a substitute. A correlation from Basu and Fraser [24] was used to estimate the terminal velocity $\left(U_{t}\right)$ of the glass beads to be $0.39 \mathrm{~m} / \mathrm{s}$ by using the average particle size of $93 \mu \mathrm{m}$. The terminal velocities of the coarse particles, ilmenite, aluminum oxide, and steel shot were also estimated by using the same correlation where the smallest particle size was used, as shown in Table 2. It should be noted that the estimated terminal velocities of the coarse particles are greater than three times the terminal velocities of the glass beads. Table 3 shows the summary of the experimental result on elutriation test.

\section{Results and discussion}

Figure 3 illustrates the typical cumulative mass of glass beads entrained from the bed as a function of time at three different $U_{g} / U_{t}$ (here $U_{t}$ is the terminal velocity of the $93 \mu \mathrm{m}$ glass bead). The data indicate that there is a nonlinear rate of increase in the mass of fines as a 
function of time. It was observed that the rate of accumulated fines was significantly higher at greater $U_{g} / U_{t}$. While the weight of $90 \mathrm{~g}$ fines was achieved in $20 \mathrm{sec}$ at $U_{g} / U_{t}=2$, the same weight was achievable after $5 \mathrm{sec}$ at $U_{g} / U_{t}=3$. The weight change was due to an increase in gas velocity. At higher gas velocities, the larger fine particles become elutriable increasing the amount of entraineable fines. In Figure 3, initially the finer particles preferentially elutriated because of their smaller terminal velocity. As fluidization time increases, the larger fine particles also contribute to entrainment. It can be seen in Figure 3 that at low times the trend lines are linear and then the slope decreases at later times. Specifically for the $\mathrm{Ug} / \mathrm{Ut}=3$ line, the slope is approximately $10 \mathrm{~g} / \mathrm{s}$ for the first 15 seconds and then drops off to zero at a time of about $40 \mathrm{~s}$. That is, the elutriation rate is initially constant when there is a sufficient amount of fines in the bed and then drops off to zero as the fines are eliminated. This linear rate of elutriation $(10 \mathrm{~g} / \mathrm{s}$ for the example) implies that steady state elutriation is nearly instantaneously achieved and only deviated from this when the fines concentration remaining in the bed gets sufficiently low such that the rate falls off. The data for the case $\mathrm{Ug} / \mathrm{Ut}=2$ is nearly linear over the entire $60 \mathrm{~s}$ test period with the slope only falling off around a time of $50 \mathrm{~s}$.

Figure 4 illustrates the effect of the loading of fine fractions on the mass of fines entrained from the bed for three different times $(20,40$, and $60 \mathrm{~s})$ at given $U_{g} / U_{t}=2.5$. In this figure, an increase in entrained fines can be observed when loading of fine fraction increased. Figure 4 also shows that as the fluidization time increases, the elutriation rate decreases because the concentration of fines in the bed decreases.

\subsection{The elutriation model}

A number of models have been proposed by Leva [25], Wen and Hashinger [15], Liu and Kimura [18], and Colakyan et al. [26] on the basis of a first order equation to described elutriation from a fluidized bed. Kato et al. [27] proposed the following model:

$$
\frac{d W_{f}}{d t}=k W_{f}
$$

where $W_{f}$ is the mass of fines remaining in the bed at time $t$ and $k$ is the elutriation rate constant. The equation (2) may also be written as;

$$
\frac{d W_{e}}{d t}=-\frac{d W_{f}}{d t}
$$

where $W_{e}$ is the cumulative mass of fine particles carried out of the bed at time $t$. Integrating Eqs (2) and (3) with initial conditions: $W_{e}=0$ and $W_{f}=W_{f o}$ at $t=0$, we obtained:

$$
W_{e}=W_{f 0}\left(1-e^{-k t}\right)
$$

where $W_{f 0}$ is the initial total mass of fines in the bed.

Equation (4) can also be written as: 


$$
\ln \left(1-\frac{W_{e}}{W_{f 0}}\right)=-k t
$$

Using Eq. (5), one can determine the elutriation rate constant, $k$, from the slope of the straight

line of $\ln \left(1-\frac{W_{e}}{W_{f 0}}\right)$ vs $t$. Then the elutriation rate constant of fines leaving the bed can be obtained as:

$$
K^{*}=\frac{k W_{f 0}}{A_{b}}
$$

Plotting $\ln \left(1-\frac{W_{e}}{W_{f 0}}\right)$ vs $t$ at different $U_{g} / U_{t}$ (Fig. 5) indicate that a linear relationship exists for all the $U_{g} / U_{t}$. This figure provides the elutriation rate constant, $k$, for $U_{g} / U_{t}$ range of 1-1.5 with $57.3 \%$ glass beads fine mixed with $\mathrm{Al}_{2} \mathrm{O}_{3}$ (small) coarse particles. Knowing $k$, $W_{f o}$, and $A_{b}$, the elutriation rate constant of fines $\left(K^{*}, \mathrm{~kg} / \mathrm{m}^{2} \mathrm{~s}\right)$ leaving the bed can be obtained using Eq. (6). Figure 6 is a typical example showing the effect of $U_{g} / U_{t}$ on elutriation rate constant $K^{*}$. The elutriation rate constant $K^{*}$, increases with $U_{g} / U_{t}$, confirming that higher $U_{g} / U_{t}$ entrained more elutriable fines. For $U_{g} / U_{t}$ larger than 2, the elutriation rate constant has noticeable increase with $U_{g} / U_{t}$. Figure 6 also shows that the relationship between the elutriation rate constant, $K^{*}$ and $U_{g} / U_{t}$ can be described as power law with $\mathrm{R}^{2}>99.9 \%$. It should be noted that the elutriation rate constant was independent of what the coarse material size was used in the experiments (Figure 6).

Figure 7 illustrates the relationship between the elutriation rate constant, $K^{*}$, and the initial loading of glass bead fines in the bed at two different $U_{g} / U_{t}$, namely, 2 and 2.5 . The elutriation rate was slow at lower initial loading of fines (0-0.5) and then improved with additional loading as shown in Figure 6. This figure also shows that the rate of elutriation is faster for higher $U_{g} / U_{t}$ at higher initial loading of fines due to increasing the gas draft forces. Figure 6 also indicate that the relationship between the elutriation rate constant, $K^{*}$ and $X_{0}$ can be described as power law with $\mathrm{R}^{2}>95 \%$.

\subsection{Proposed correlation of the elutriation rate constant, $K^{*}$}

In order to obtain a correlation that defines the elutriation rate constant, $K_{\text {elu }}^{*}$, as a function of operating parameters, such as gas velocity, initial loading of fines, and properties of the gas and the solids, etc. attempts were made to correlate the experimental, $K_{\text {elu }}^{*}$, with appropriate operating parameters. Correlations are useful because they can indicate a predictive relationship that can be exploited in practice A statistical approach such as cross-correlation matrix was used to determine which of the dimensionless parameters were relevant, namely, $X_{0}, U_{g} / U_{t}, d p_{\text {fine }} / d p_{\text {coarse }}$, and $\rho_{\text {fine }} / \rho_{\text {coarse }}$, to the development of the elutriation rate constant, $K^{*}$ elu.

In trying to find a reliable and more general correlation for $K^{*}$ elu, various dimensionless groups that might give unified representation of the experimental data were tested. The most important 
experimental quantities measured were superficial gas velocity, initial loading of fines, and particle properties. Dimensionless parameters included in this analyses were $X_{0}, U_{g} / U_{t}$, the ratio of fine to coarse particles ( $\mathrm{dp}_{\text {fine }} / \mathrm{dp}_{\text {coarse }}$ ), and the ratio of the fine to coarse particle density $\rho_{\text {fine }} / \rho_{\text {coarse. }}$.

Based on the above considerations, Table 4 presents the cross-correlation matrix for the independent variables in predicting, $K^{*}$ elu. The general rule of thumb is that the cross correlation coefficient should lie between -0.7 and 0.7 to eliminate standard error estimates associated with the co-linearity of the independent variables [28]. Table 4 shows that the cross correlation coefficients are within this rule of thumb. Therefore, the following correlation is proposed to correlate the elutriation rate constant, $K_{\text {elu }}^{*}$, as;

$$
K_{\text {elu }}^{*}\left(k g / m^{2} s\right)=0.384\left(X_{0}\right)^{1.386}\left(\frac{U_{g}}{U_{t}}\right)^{2.652}\left(\frac{d p_{\text {fine }}}{d p_{\text {coarse }}}\right)^{0.133}\left(\frac{\rho_{\text {fine }}}{\rho_{\text {coarse }}}\right)^{-0.459}
$$

Equation 7 could be simplified within the statistical significance of the data such that the exponent on the $3^{\text {rd }}$ term could be discarded, as it did not contribute significantly to the variance explained. Therefore, the Eq. (7) was further reduced to:

$$
K_{\text {elu }}^{*}\left(k g / m^{2} s\right)=0.354\left(X_{0}\right)^{1.366}\left(\frac{U_{g}}{U_{t}}\right)^{2.586}\left(\frac{\rho_{\text {fine }}}{\rho_{\text {coarse }}}\right)^{-0.444}
$$

The coefficients were taken as the average of the upper and lower limits for the $95 \%$ confidence limits. The coefficients are $0.354 \pm 0.663,1.366 \pm 0.499,2.586 \pm 0.416$, and $-0.444 \pm 3.667$ for each term, respectively. The initial loading of fines, $X_{0}$, and $U_{g} / U_{t}$ were the strongest factors determining the elutriation rate constant, $K_{\text {elu. }}^{*}$ The rate constant was proportionally related to both $X_{0}$, and $U_{g} / U_{t}$; the higher $X_{0}$, and $U_{g} / U_{t}$ the larger the elutriation rate constant, $K^{*}$ elu.

The comparison between the experimental data on the elutriation rate constant, $K_{\text {elu }}^{*}$, and the predicted of Eq. (8) is illustrated in Fig. 8. Agreement is good with variance explained $\left(\mathrm{R}^{2}\right)$ of $96 \%$.

The correlation developed by Choi et al. [29] is also tested for each experimental conditions (Fig. 9). The correlation given by Choi el al. [29] for the elutriation rate constant is

$$
K_{\text {elu }}^{*}\left(k g / m^{2} s\right)=0.36\left(X_{0}\right)^{1.09}\left(\frac{U_{g}-U_{t}}{U_{t}}\right)^{3.83}
$$

The Choi et al. [29] correlation under predicts the elutriation rate constant in most of the test cases used in this study. The deviation may results from the density difference between the two studies. In their study, nickel ammonium sulfate with specific gravity of 1.923 with different sizes and sphercities was used. Therefore, attempt were made to include the values of $\rho_{\text {fine }} / \rho_{\text {coarse }}$ of this study to Choi's et al. correlation. Figure 10 compares our experimental data with corrected Choi's et al. and shows that their correlation with addition of $\rho_{\text {fine }} / \rho_{\text {coarse }}$ improve the fits of the experimental data by $45 \%$. 
The comparison to most of the correlations in the literature with this study have been excluded because of their proposed correlations belong to one particle system of same densities.

\section{Conclusion}

The elutriation of fines of two particle system of different densities was investigated in a cold flow bubbling fluidized bed. The coarse particles were $\mathrm{Al}_{2} \mathrm{O}_{3}$ of two different sizes (613 and 309 $\mu \mathrm{m})$, ilmenite $(155 \mu \mathrm{m})$ and steel shot $(200 \mu \mathrm{m})$. The fine particles were glass beads with an average particle size of $93 \mu \mathrm{m}$. The elutriation rate of the fine particles increased with increasing the $U_{g} / U_{t}$ and the initial loading of fines. The coarse particle sizes and their densities had a minor effect upon elutriation of fine particles. In this study, the first order rate equation was used to

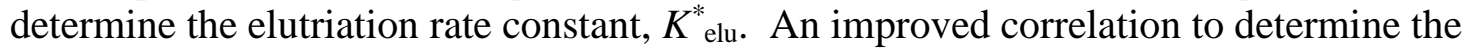
elutriation rate of the fine particles was proposed correlating with $U_{g} / U_{t}$, initial loading of fines, and densities ratio of coarse and fine particles. The correlation was better predictable than previous one and cover the wider range of $U_{g} / U_{t}$ especially for $U_{g} / U_{t} \leq 1$.

\section{Disclaimer}

The authors declare no competing financial interest. The U.S. Department of Energy, NETL, and REM contributions to this paper were prepared as an account of work sponsored by an agency of the United States Government. Neither the United States Government nor any agency thereof, nor any of their employees, makes any warranty, express or implied, or assumes any legal liability or responsibility for the accuracy, completeness, or usefulness of any information, apparatus, product, or process disclosed, or represents that its use would not infringe privately owned rights. Reference herein to any specific commercial product, process, or service by trade name, trademark, manufacturer, or otherwise does not necessarily constitute or imply its endorsement, recommendation, or favoring by the United States Government or any agency thereof. The views and opinions of authors expressed herein do not necessarily state or reflect those of the United States Government or any agency thereof.

\section{Acknowledgment}

The authors acknowledge the Department of Energy for funding the research through the office of Fossil Energy's Gasification Technology and Advanced Research funding programs. Special thanks go to Douglas Straub, and Joseph S. Mei for their assistance with experimental work and data.

\section{Notation}

$A_{b} \quad$ cross-sectional area of bed $\left(\mathrm{m}^{2}\right)$

$\mathrm{D}_{\mathrm{b}} \quad$ bed diameter $(\mathrm{m})$

$\mathrm{dp}_{\text {coarse }}$ particle mean size of coarse particle $(\mathrm{m})$

$\mathrm{dp}_{\text {fine }}$ particle mean size of fine particle $(\mathrm{m})$

$k \quad$ rate constant $(1 / \mathrm{s})$

$K^{*}$ elu elutriation rate constant $\left(\mathrm{kg} / \mathrm{m}^{2} \mathrm{~s}\right)$

$t$ time (s)

$\mathrm{TDH}-$ transport disengaging height $(\mathrm{m})$ 
$U_{g} \quad$ superficial gas velocity $(\mathrm{m} / \mathrm{s})$

$U_{t} \quad$ terminal velocity of fine material $(\mathrm{m} / \mathrm{s})$

$W_{e} \quad$ cumulative mass of fine particles $(\mathrm{g})$

$W_{f} \quad$ mass of fines remaining in the bed at time $t(\mathrm{~g})$

$X_{0} \quad$ initial weight fraction of fines

Greek symbol

$\rho_{\text {coarse }}$ particle density of coarse particle $\left(\mathrm{g} / \mathrm{cm}^{3}\right)$

$\rho_{\text {fine }} \quad$ particle density of fine particle $\left(\mathrm{g} / \mathrm{cm}^{3}\right)$

\section{References}

[1] H. E. J.Andrus, J. H. Chiu, P. R. Thibeault, A. Brutsch, Alstom's calcium oxide chemical looping combustion coal power technology development. Proceedings of the 34th International Technical Conference on Clean Coal and Fuel Systems; Clearwater, FL, May 31-June 4, 2009. [2] H. J. Richter, K. F. Knoche, Reversibility of combustion processes. In Efficiency and Costing: Second Law Analysis of Processes. Gaggioli, R. A., Ed.; American Chemical Society: Washington, D.C., 1983, ACS Symposium Series, Vol. 235, Chapter 3, pp 71-85.

[3] A. Lyngfelt, B. Leckner, T. Mattisson, A fluidized-bed combustion process with inherent $\mathrm{CO}_{2}$ separation; application of chemical-looping combustion, Chem. Eng. Sci. 56 (2001) 31013113.

[4] L. S. Fan, Chemical Looping Systems for Fossil Fuel Conversion, Wiley and Sons, 2010. [5] M. Hossain, H. de Lasa, Chemical-Looping Combustion (CLC) for Inherent CO2 Separations - A Review, Chem. Eng. Sci. 63 (2008) 4433-4451.

[6] R. Siriwardane, H. J. Tian, G. Richards, T. Simonyi, J. Poston, Chemical-Looping Combustion of Coal with Metal Oxide Oxygen Carriers, Energy \& Fuels 23 (2009) 3885-3892. [7] A. Rubel, K. L. Liu, J. Neatherya, D. Taulbeea, Oxygen carriers for chemical looping combustion of solid fuels, Fuel 88 (2009) 876-884.

[8] F.A. Zenz, N. A. Weil, A theoretical-empirical approach to the mechanism of particle entrainment from fluidized beds, AIChE J. 4 (1958) 472-479.

[9] D. Geldart, J. Cullinan, S. Georghiades, D. Gilvray, D. J. Pope, Effect of fines on entrainment from gas-fluidized beds, Trans. Inst. Chem. Eng. 57 (1979) 269-275.

[10] M. Colakyan, O. Levenspiel, Elutriation from fluidized-beds, Powder Technol. 38 (1984) 223-232.

[11] S. E. George, J. R. Grace, Entrainment of particles from a pilot scale fluidized bed, Can. J. Chem. Eng. 59 (1981) 279-284.

[12] L. Lin, J. T. Sears, C.Y. Wen, Elutriation and attrition of char from a large fluidized bed, Powder Technol. 27 (1980) 105-115.

[13] S. M. Tasirin, D. Geldart, The elutriation of fine and cohesive particles from gas fluidized beds, Chem. Eng. Commun. 173 (1999) 175-195.

[14] V. Stojkovski, Z. Kostic, Empirical correlation for prediction of the elutriation rate constant, Thermal Sci. 7 (2003) 43-58.

[15] C.Y. Wen, R.F. Hashinger, Elutriation of solid particles from a dense-phase fluidized bed, AIChE J. 6 (1960) 220-226. 
[16] J. W. Chew, A. Cahyadi, C. M. Hrenya, R. Karr, R. A. Cocco, Review of entrainment correlations in gas-solid fluidization, Chem. Eng. J. 260 (2015) 152-171.

[17] D. Geldart, J. Cullinan, S. Georghiades, D. Gilvray, D. J. Pope, The effect of fines on entrainment from gas fluidised beds, Trans. I. Chem. E. 57 (1979) 269-275.

[18] Y.D. Liu, S. Kimura, Fluidization and entrainment of difficult-to-fluidize fine powder mixed with easy-to fluidize large particle, Powder Technol. 75 (1993) 189-196.

[19] D. Geldart, D.J. Pope, Interaction of fine and coarse particles in the freeboard of a fluidized bed, Powder Technol. 34 (1983) 95-97.

[20] J. Li, T. Nakazato, K. Kato, Effect of cohesive powders on the elutriation of particles from a fluid bed, Chem. Eng. Sci. 59 (2004) 2777-2782.

[21] D. Geldart, N. Harnby, A.C. Wong, Fluidization of cohesive powders, Powder Technol. 37 (1987) 25-37.

[22] R. Cocco, F. Shaffer, R. Hays, S. B. R. Karri, T. Knowlton, Particle clusters in and above fluidized beds. Powder Technol. 203 (2010) 3-11.

[23] C.K. Ko, Hydrodynamics in Bubbling and Circulating Fluidized Beds and Cyclone Performance of Iron Ore Particles, Department of Chemical and Biomolecular

Engineering, KAIST, Seoul, 2012.

[24] P. Basu, S. A. Fraser, Circulating Fluidized Bed Boilers: Design and Operations.

Butterworth-Heinemann, 1991.

[25] M. Leva, Elutriation of fines from fluidized systems, Chem. Eng. Prog. 47 (1951)

39-45.

[26] M. Colakyan, N. Catipovic, G. Jovanovic, F. Fitzgerald, Elutriation from a large particle

fluidized bed with and without immersed heat transfer tubes, AIChE Symp. Ser. 77 (1981) 6675.

[27] K. Kato, S. Kanbara, T. Tajima, H. Shibasaki, K. Ozawa, T. Takarada, Effect of particlesize on elutriation rate-constant for a fluidized-bed, J. Chem. Eng. Jpn. 20 (1987) 498-504.

[28] D.A. Lind, W.G. Marchal, S.A. Wathen, Statistical Techniques in Business and Economics, McGraw-Hill Irwin, Boston, 2005.

[29] C-S. Choi, K-P. Yoo, H-D. Jang, Elutriation of fines from a binary particle fluidized bed, Korean J. of Chem. Eng. 2 (1985) 197-200. findings on the effect of gas velocity 


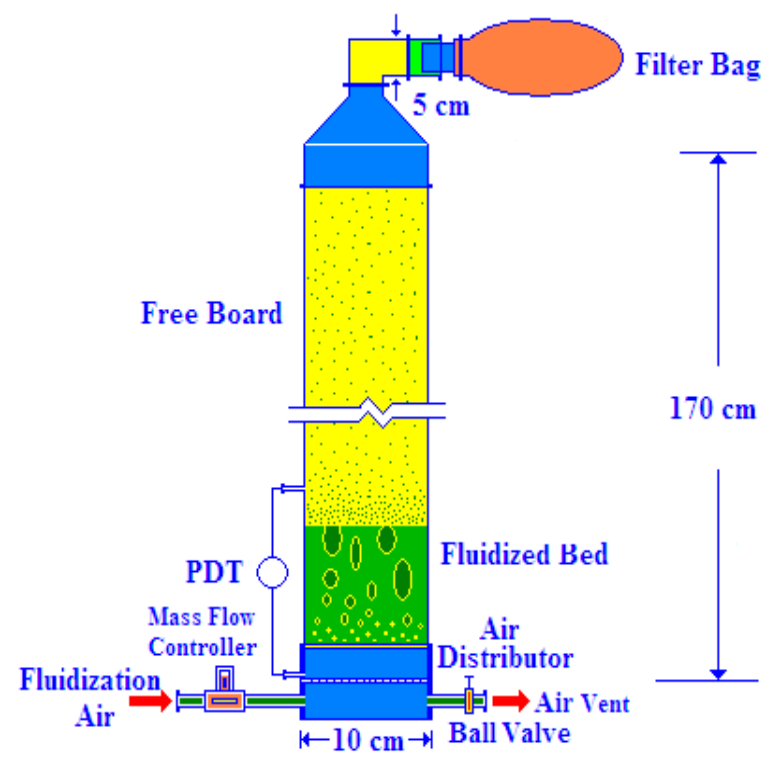

Figure 1. Schematic diagram for the $10 \mathrm{~cm}$ diameter bubbling fluidized bed 


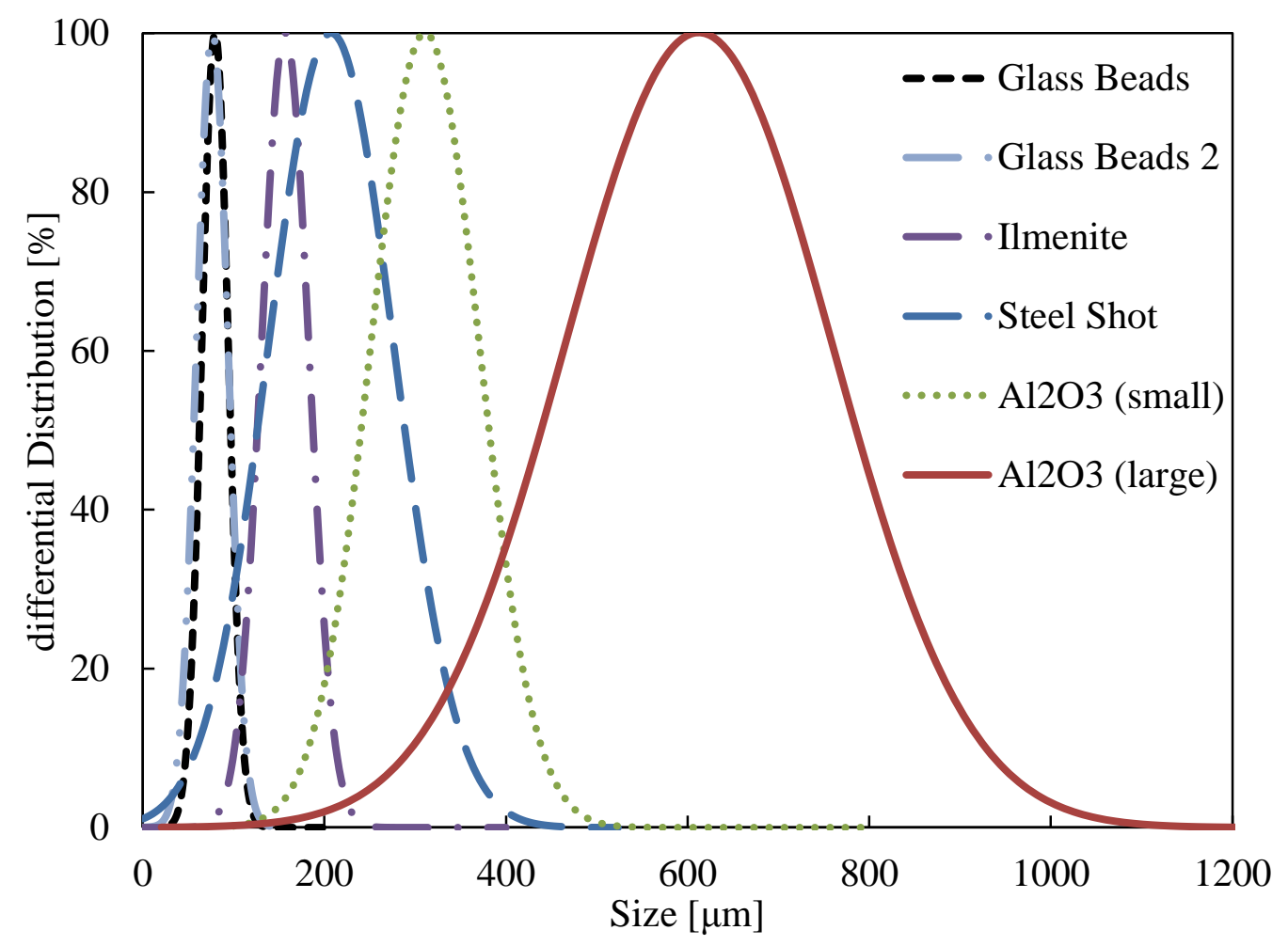

Figure 2. Initial differential particle size distributions of the material under this study. 


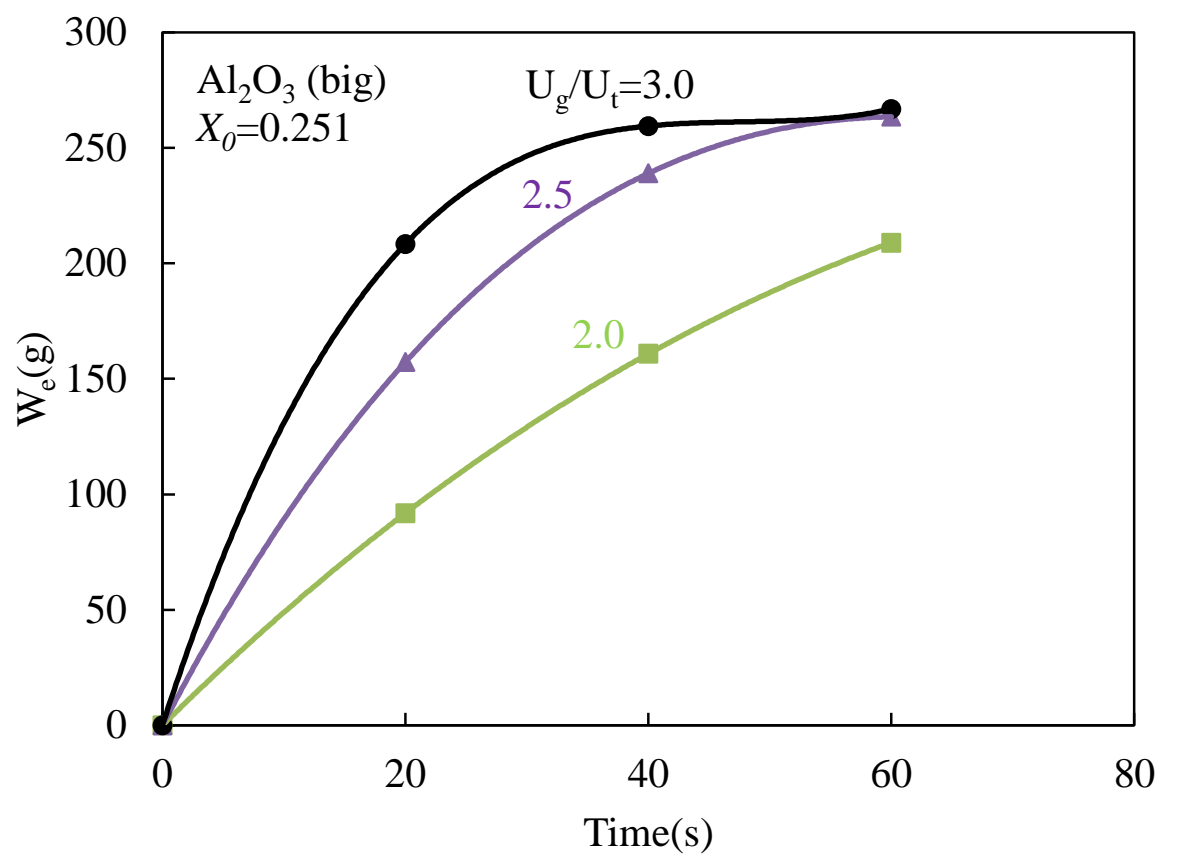

Figure 3. Elutriated cumulative weight of glass bead fines mixed with $\mathrm{Al}_{2} \mathrm{O}_{3}(\mathrm{big}), W_{e}$, versus time. 


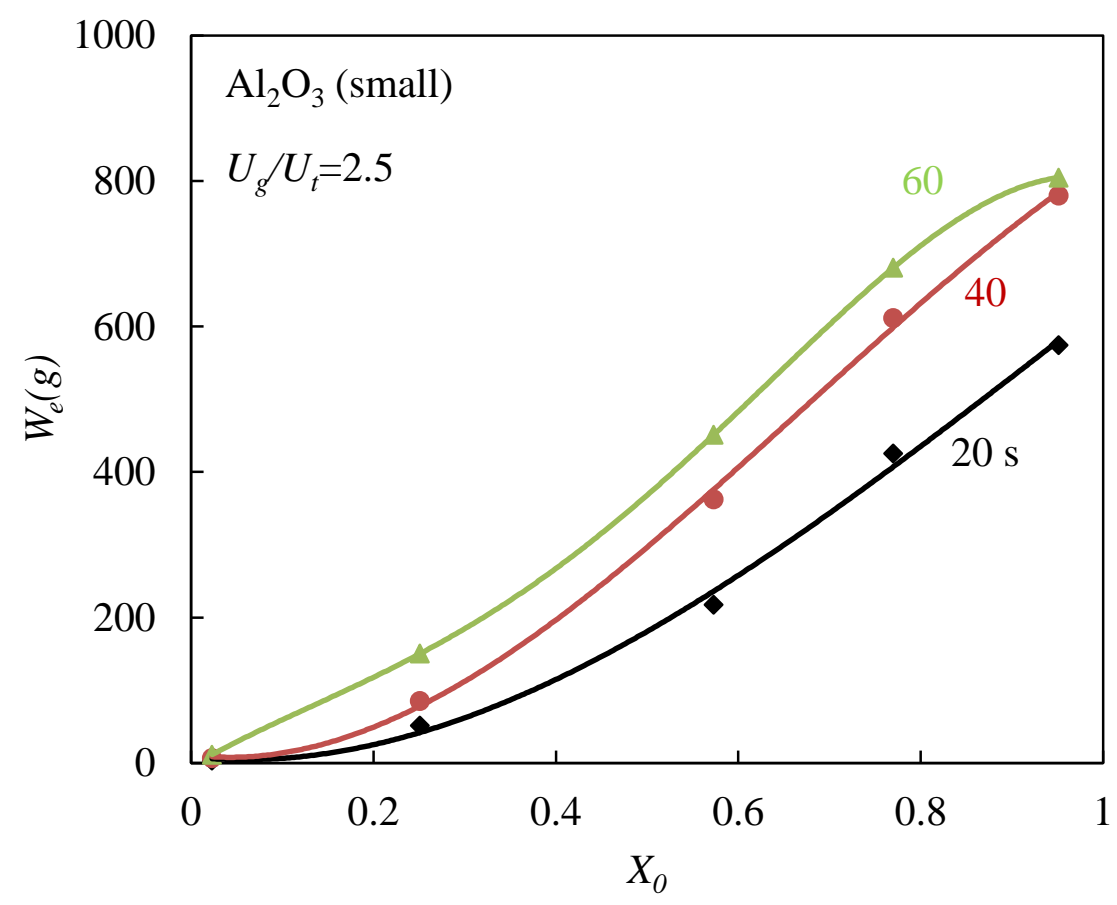

Figure 4. Variation of the cumulative weight of glass bead fines with the loading of fine powders in the bed with time. 


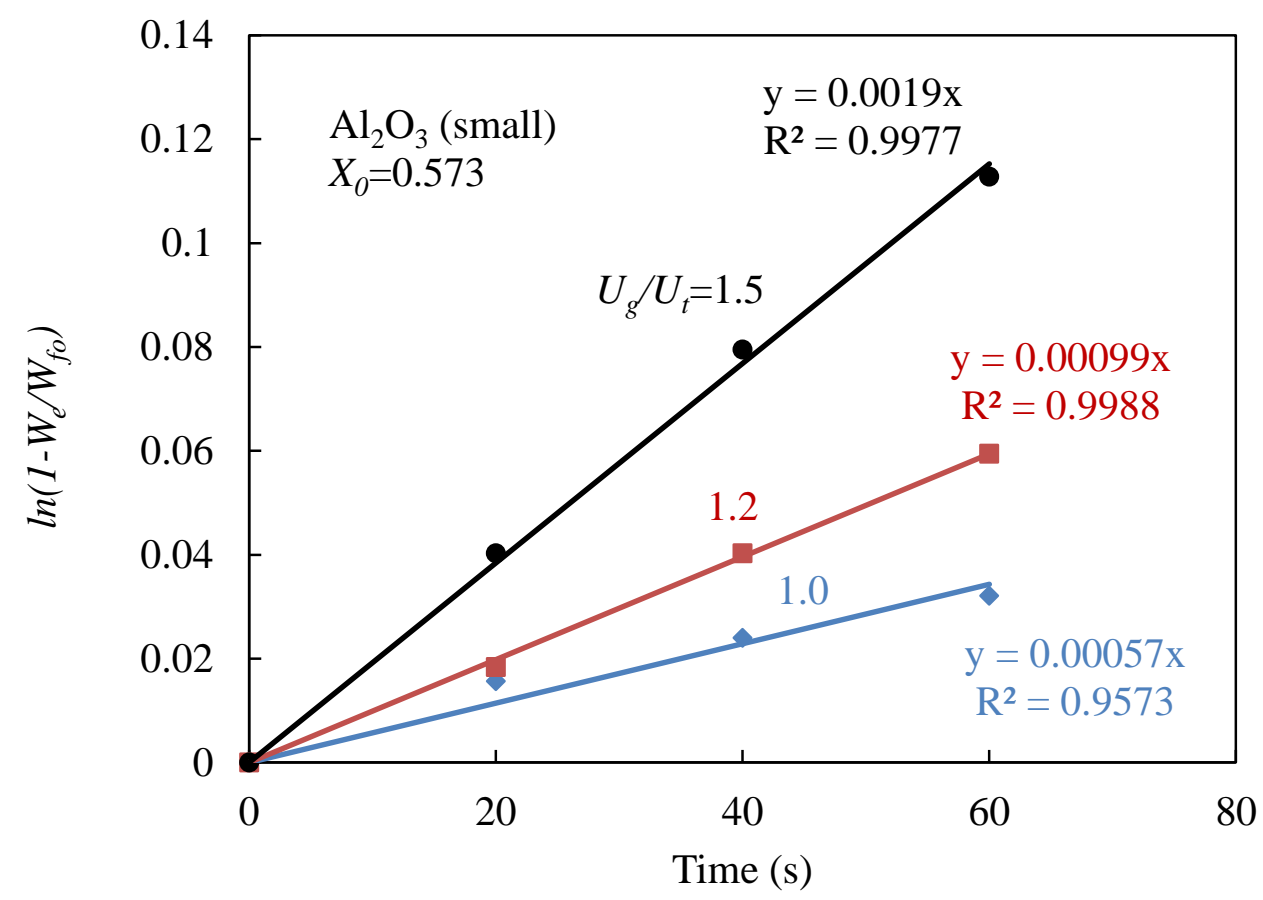

Figure 5. Linear plot to exam first-order elutriation on the basis of Eq. (5). 


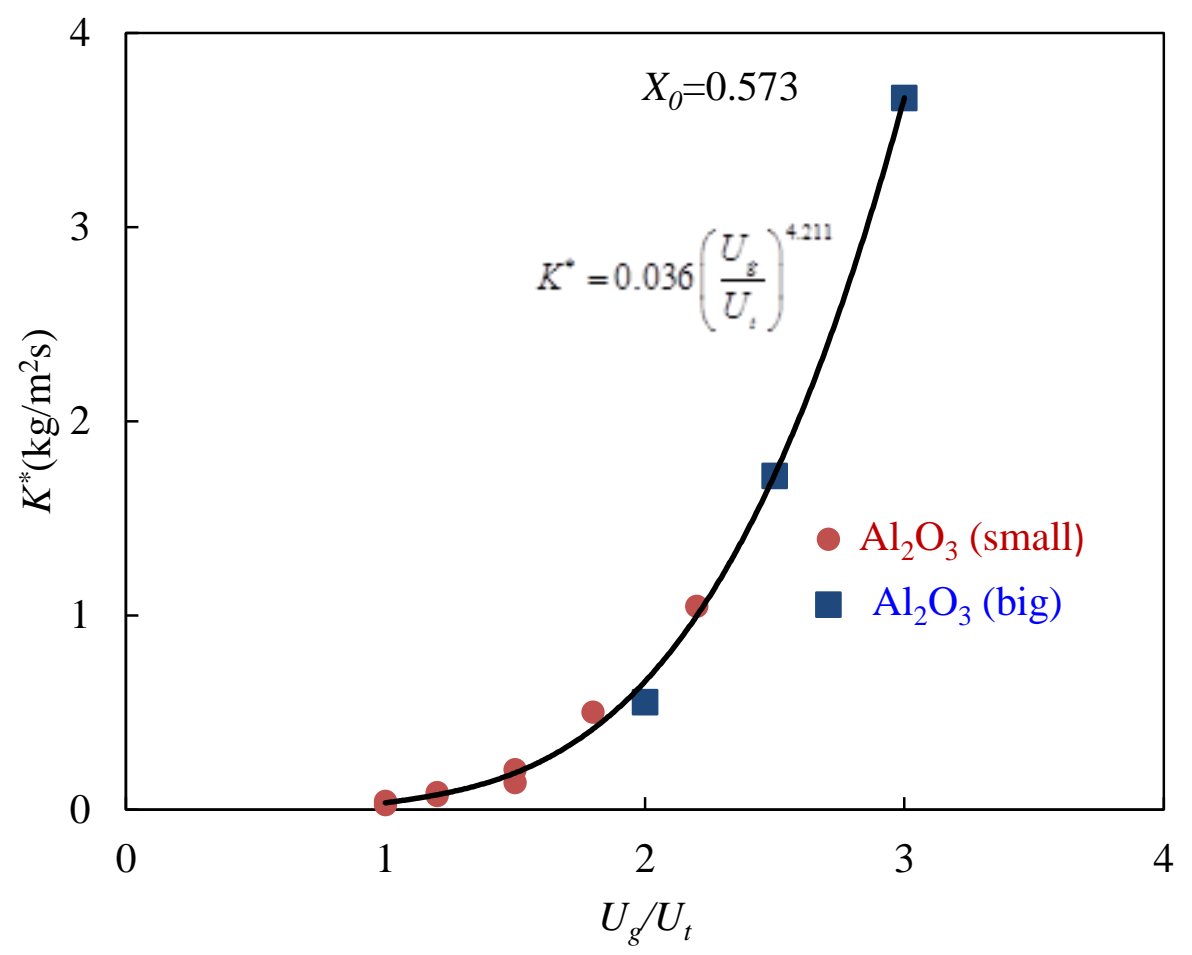

Figure 6. Effect of $U_{g} / U_{t}$ on the elutriation rate constant 


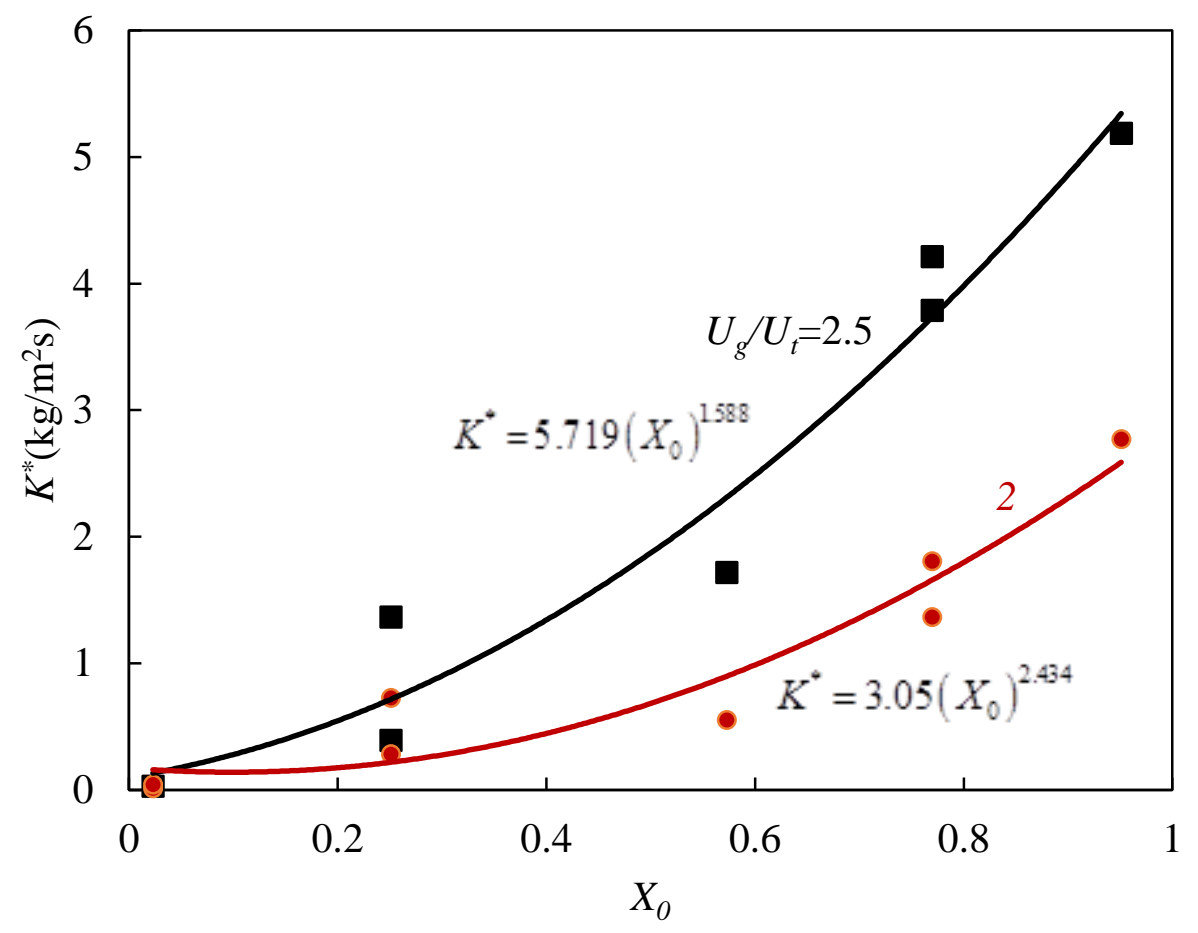

Figure 7. Effect of initial loading of fines, $X_{0}$, on the elutriation rate constant for two different $U_{g} / U_{t}$ 


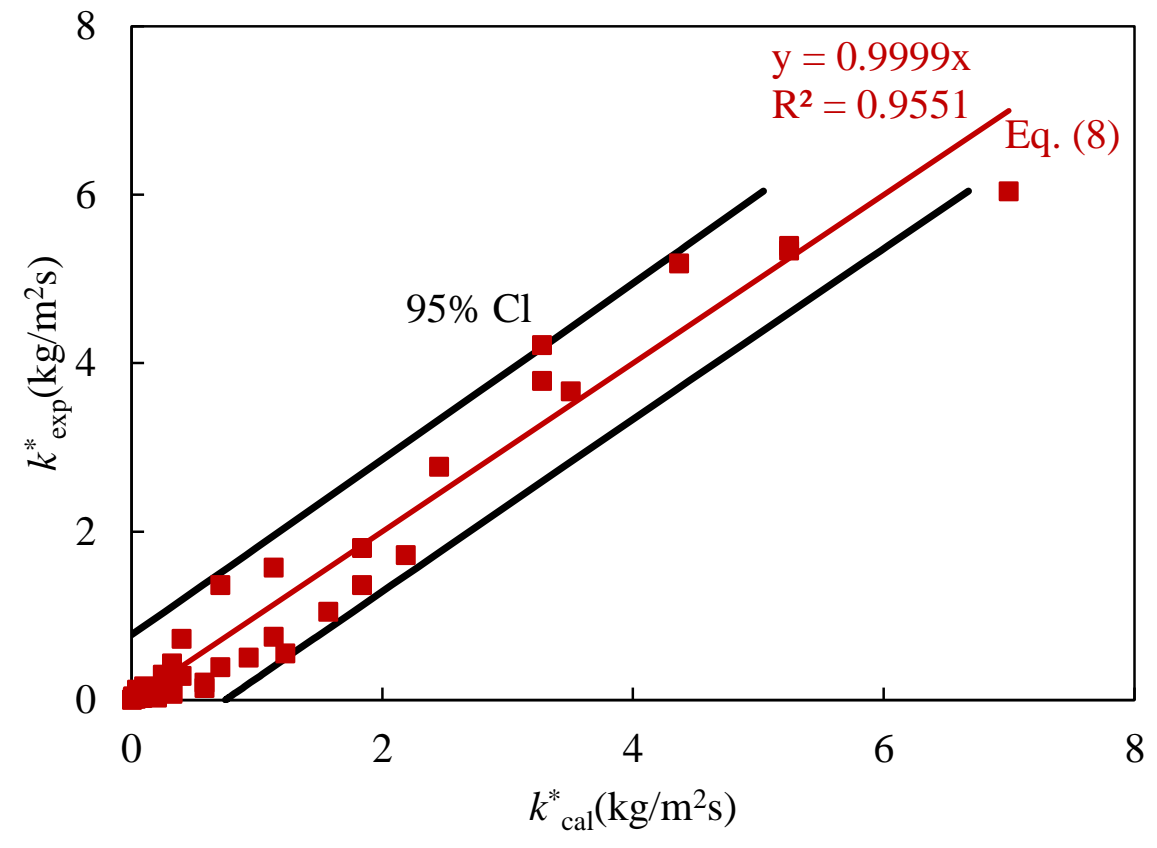

Figure 8. Comparison of the elutriation rate constant using Eq. (8) with experimentally measured values. 


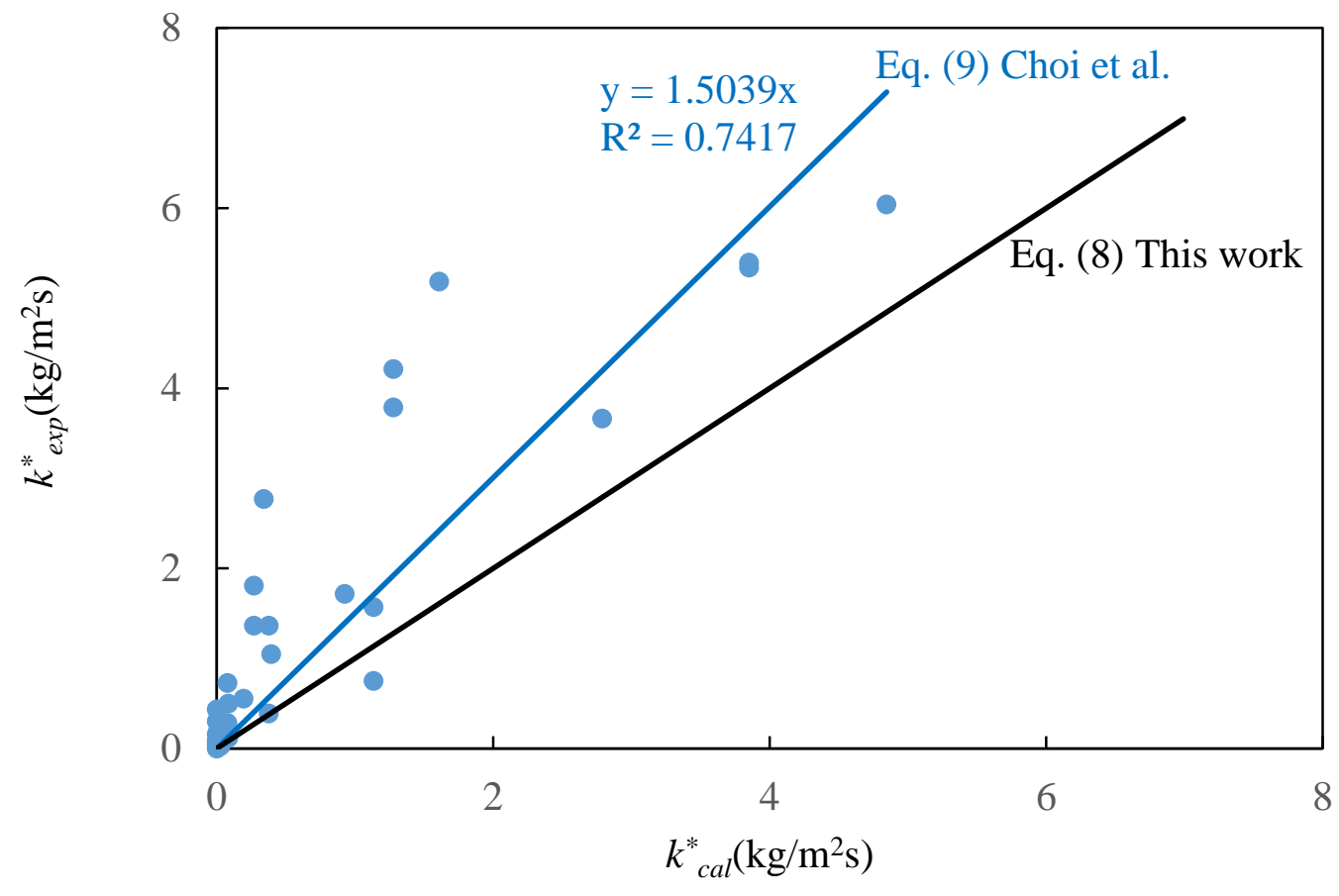

Figure 9. Comparison of the elutriation rate constant using Eq. (9) developed by Choi et al. [29] with experimentally measured values. 


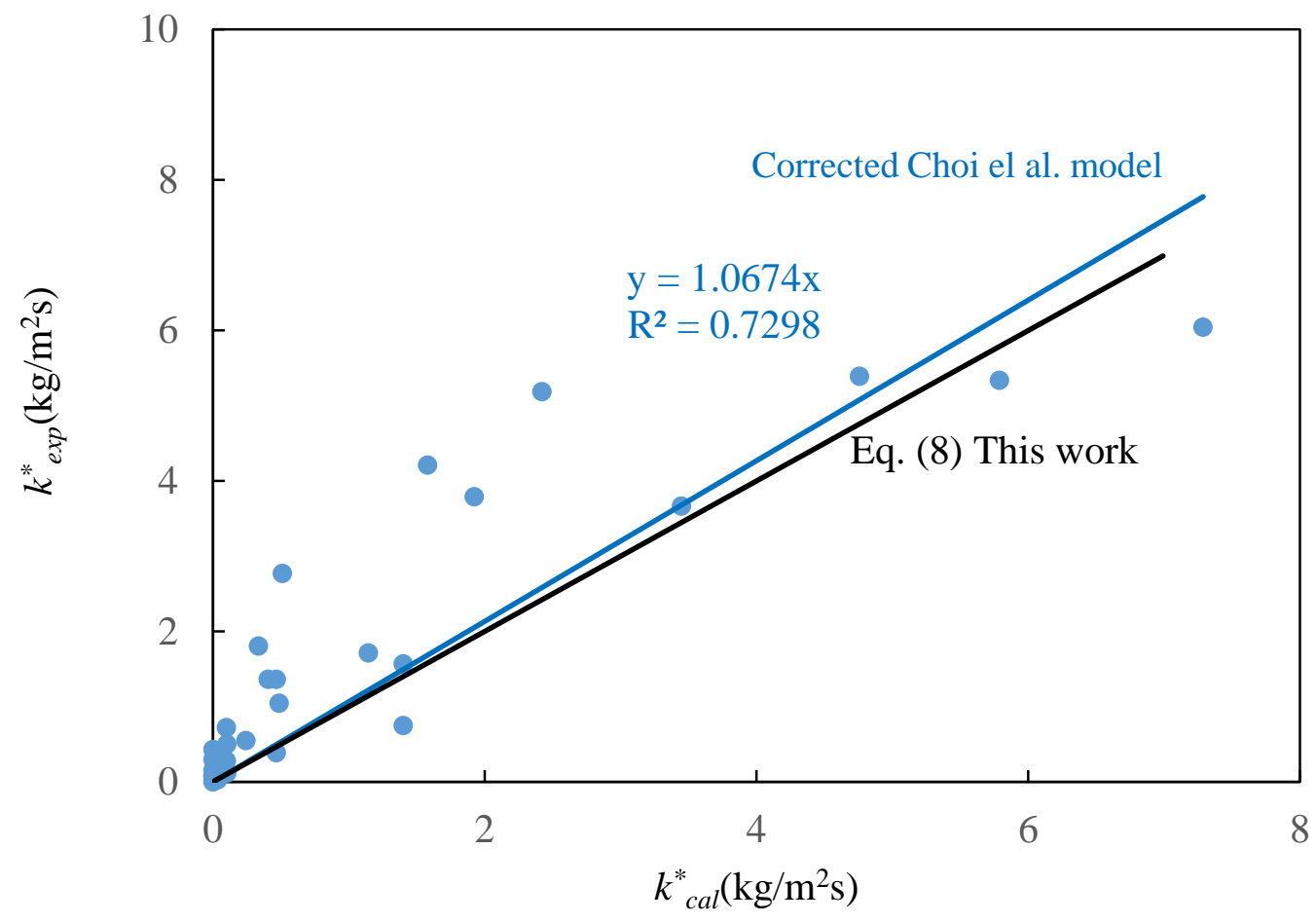

Figure 10. Comparison of the elutriation rate constant using modified model to Choi et al. [29] with experimentally measured values. 
Table 1. Physical properties of tested materials where SMD is the sauter mean diameter

\begin{tabular}{lcccccccc}
\hline \multicolumn{1}{c}{ Material } & \multicolumn{4}{c}{ Size Range $(\mu \mathrm{m})$} & Sphericity & Density & \multicolumn{2}{c}{$\mathrm{U}_{\mathrm{t}}(\mathrm{m} / \mathrm{s})$} \\
& Max & Avg & Min & SMD* & $(-)$ & $\left(\mathrm{kg} / \mathrm{m}^{3}\right)$ & Largest & Smallest \\
\hline Steel Shot & 360 & 200 & 105 & 194.39 & 0.923 & 7890 & $\mathrm{X}$ & 1.78 \\
Ilmenite & 250 & 155 & 105 & 151.24 & 0.902 & 4457 & $\mathrm{X}$ & 1.24 \\
$\mathrm{Al}_{2} \mathrm{O}_{3}$ (small) & 500 & 309 & 149 & 293.97 & 0.821 & 3968 & $\mathrm{X}$ & 1.6 \\
$\mathrm{Al}_{2} \mathrm{O}_{3}$ (large) & 1000 & 613 & 300 & 550.56 & 0.820 & 3968 & $\mathrm{X}$ & 3.18 \\
Glass Beads & 123 & 93 & 37 & 75.3 & 0.912 & 2464 & 0.39 & $\mathrm{X}$ \\
\hline
\end{tabular}

*Sauter mean diameter 
Table 2. Experimental conditions.

\begin{tabular}{|c|c|c|c|c|}
\hline & $\begin{array}{l}\text { Steel Shot / } \\
\text { Glass Beads }\end{array}$ & $\begin{array}{l}\text { Ilmenite / } \\
\text { Glass Beads }\end{array}$ & $\begin{array}{l}1000 \times 300 \mu \mathrm{m} \\
\mathrm{Al}_{2} \mathrm{O}_{3} / \text { Glass } \\
\text { Beads }\end{array}$ & $\begin{array}{l}500 \times 149 \mu \mathrm{m} \\
\mathrm{Al}_{2} \mathrm{O}_{3} / \text { Glass } \\
\text { Beads }\end{array}$ \\
\hline Static bed depth $(\mathrm{cm})$ & 7.62 & 7.62 & 7.62 & 7.62 \\
\hline Aspect Ratio, L/D (-) & 0.75 & 0.75 & 0.75 & 0.75 \\
\hline $\begin{array}{l}\text { Dimensionless } \\
\text { velocity, } \\
U_{g} / U_{t \_\mathrm{gb}}(-)\end{array}$ & $0.8,1.0,1.2$ & $0.8,1.0,1.2$ & $\begin{array}{l}1.0,1.2,1.5,1.8, \\
2.0,2.2,2.5,3.0\end{array}$ & $\begin{array}{l}1.0,1.2,1.5,2.0 \text {, } \\
2.5,3.0\end{array}$ \\
\hline Gas Velocities $(\mathrm{m} / \mathrm{s})$ & $\begin{array}{l}0.31,0.39 \\
0.47\end{array}$ & $\begin{array}{l}0.31,0.39 \\
0.47\end{array}$ & $\begin{array}{l}0.39,0.47,0.59 \\
0.70,0.78,0.86 \\
0.98,1.17\end{array}$ & $\begin{array}{l}0.39,0.47,0.59 \\
0.78,0.98,1.17\end{array}$ \\
\hline $\begin{array}{l}\text { Percentage of Glass } \\
\text { Beads (wt } \% \text { ) }\end{array}$ & 57 & 57 & $2,25,57,77$ & $2,25,57,77,95$ \\
\hline
\end{tabular}


Table 3. Summary of the experimental result on elutriation test. $U_{t}$ is a calculate value of glass bead using $d_{p}=93 \mu \mathrm{m}$.




Table 4. Cross correlation matrix for elutriation rate constant relationship.

\begin{tabular}{lrrrrr}
\hline & $K^{*}{ }_{\text {elu }}\left(\mathrm{kg} / \mathrm{m}^{2} \mathrm{~s}\right)$ & \multicolumn{1}{c}{$X_{0}$} & $U_{g} / U_{t}$ & $d p_{\text {coarse }} / d p_{\text {fine }}$ & $\rho_{\text {fine }} / \rho_{\text {coarse }}$ \\
\hline$K^{*}{ }_{\text {elu }}\left(\mathrm{kg} / \mathrm{m}^{2} \mathrm{~s}\right)$ & 1.0 & & & & \\
$X_{0}$ & 0.615 & 1.0 & & & \\
$U_{g} / U_{t}$ & 0.659 & 0.182 & 1.0 & & \\
$d p_{\text {coarse }} / d p_{\text {fine }}$ & 0.413 & 0.252 & 0.671 & 1.0 & \\
$\rho_{\text {fine }} / \rho_{\text {coarse }}$ & 0.242 & 0.110 & 0.502 & 0.192 & 1.0 \\
\hline
\end{tabular}






